\title{
Aquisição e processamento da linguagem: uma abordagem integrada sob a ótica minimalista
}

Letícia Maria Sicuro Corrêa (PUC-Rio, LAPAL)

Recebido 15, fev. 2011/Aprovado, 7 mar. 2011

\section{Resumo}

A aquisição de uma língua é vista como um problema de aprendibilidade que requer um tratamento conjunto por parte de teorias linguística e psicolinguística. Dificuldades no relacionamento entre esses campos são apontadas, as quais têm impedido sua efetiva integração no tratamento desse problema. Uma abordagem integrada é proposta em que se articula a hipótese do bootstrapping fonológico com uma concepção minimalista de língua. A distinção entre classes abertas e fechadas do léxico na análise do sinal da fala ao fim do primeiro ano de vida é tida como fundamental para a inicialização de um sistema computacional universal. $O$ desenvolvimento linguístico é apresentado como a progressiva especificação dos traços formais de categorias funcionais via o processamento nas interfaces fônica e semântica. Direcionamentos para a pesquisa em aquisição da linguagem a partir dessa abordagem são apontados.

Palavras-chave: aquisição da linguagem; aprendibilidade; aprendizagem guiada por fatores inatos; desencadeamento (bootstrapping); minimalismo; interface fônica; interface semântica; traços formais. 


\section{Introdução}

Este artigo foi desenvolvido a partir da palestra proferida na Mesa-Redonda Linguagem e Cognição: Teorias, métodos e práticas, por ocasião da $1^{a}$ Jornada do Programa de Pós-Graduação em Estudos da Linguagem da UFF ${ }^{1}$ e é, em grande parte, uma re-edição do conteúdo apresentado em Corrêa (2009a; 2009b)². Os objetivos daquela palestra foram: (i) introduzir o problema que a aquisição de uma língua apresenta; (ii) chamar atenção para a necessidade de um diálogo mais estreito entre teorias linguística e psicolinguística no tratamento desse problema; (iii) apresentar o que denominamos uma abordagem integrada, ${ }^{3}$ em que se considera a aquisição da linguagem a partir do processamento do material linguístico pela criança, à luz de uma concepção de minimalista de língua; (iv) ilustrar a metodologia utilizada nessa abordagem. Neste artigo, esses objetivos se mantêm, exceto o último, dado que informação pertinente a este pode ser obtida em muitas das referências citadas.

A perspectiva teórica aqui apresentada define um programa de pesquisa que nos parece promissor, tendo em vista que dá origem a estudos pontuais de aquisição da linguagem, com tópicos específicos (gênero, número, aspecto gramatical, por exemplo), ao estudo das possíveis relações entre a língua e os sistemas cognitivos com os quais interage no curso do desenvolvimento línguistico/cognitivo, assim como possibilita a formulação de hipóteses acerca de problemas pertinentes ao desenvolvimento linguístico, tal como o Déficit Específico da Linguagem (DEL) (cf. CORRÊA \& AUGUSTO, 2011).

Diante disso, na primeira seção, desenvolvemos conside-

A Mesa-Redonda Linguagem e Cognição: Teoria, Métodos e Práticas foi compartilhada com os professores Margarida Salomão (UFJF) e Francisco Ordonez (SUNY) e mediada pelo Prof. Eduardo Kenedy (UFF), no Campus de Gragoatá, em 20 de outubro de 2010.

2 O evento acima e a preparação deste artigo ocorreram durante a vigência de bolsa de produtividade $\mathrm{CNPq}$ 304159/2008-5.

Abordagem que caracteriza o direcionamento da pesquisa conduzida pelo GPPAL (Grupo de Pesquisa Processamento e Aquisição da Linguagem-CNPq) no LAPAL (Laboratório de Psicolinguística e Aquisição da Linguagem - PUC-Rio). rações relativas a (i) e (ii) acima, na segunda seção, focamos a abordagem integrada que orienta nossa pesquisa (iii) e, por fim, concluímos, apontando para o que nos parecem ser indícios de um melhor entendimento da natureza da linguagem e do que viabiliza a aquisição da língua materna de forma natural.

\section{Aquisição da linguagem: problema de aprendibilidade}

A aquisição da linguagem tem despertado o interesse daqueles preocupados com o desenvolvimento humano, desde o século XVIII, dando origem a registros diários da produção da linguagem pela criança no curso do desenvolvimento linguístico, os quais serviram de base para as primeiras especulações acerca da natureza desse processo (cf. BLUMENTHAL, 1970, para histórico). Foi, contudo, apenas há cerca de meio século que a aquisição da linguagem foi apresentada como um problema de aprendibilidade - o que torna uma língua passível de ser adquirida de forma natural, sem esforço ou treinamento específico, dado que, em princípio, há mais de uma gramática compatível com os dados linguísticos a que a criança tem acesso? Diante desse problema, a 
teoria linguística buscaria explicitar as propriedades que uma língua deve ter para que sua aquisição seja viável (CHOMSKY, 1965).

Teorias psicolinguísticas, por sua vez, buscariam caracterizar de que maneira esse processo transcorre, ou que propriedades do processo de aquisição o tornam factível (cf. SLOBIN, 1973; MACWHINNEY, 1987). Certamente, uma teoria do processo de aquisição da linguagem pressupõe uma concepção ou modelo de língua que uma teoria linguística preocupada com a questão da aprendibilidade poderia fornecer. Uma efetiva articulação entre teorias linguística e psicolinguística tem sido, contudo, difícil de ser estabelecida. Discutiremos a seguir possíveis razões para essa dificuldade.

O problema da aquisição da linguagem, concebido abstratamente, consiste na identificação da gramática da língua a partir de sentenças (unidades sintáticas cujos elementos se relacionam de forma hierárquica) que se apresentam como sequências de elementos do léxico (ou seja, sem que as relações hierárquicas entre estes se apresentem de forma transparente). Essa formulação do problema, ainda que deixe clara a questão de aprendibilidade que se apresenta, abstrai-se do fato de que a criança processa o material linguistico a que é exposta muito antes de ser capaz de nele reconhecer uma sequência de elementos do léxico. Os enunciados linguísticos se apresentam à criança no fluxo da fala, $o$ qual tem se ser segmentado em unidades passíveis de análise (ou seja, passíveis de serem mantidas, por limitado período de tempo, em um sistema de memória de trabalho) até que sequências de unidades do léxico possam ser tomadas como tal. A delimitação de unidades lexicais é, portanto, por si só, um problema para a criança, uma vez que esta não dispõe de um léxico constituído. Assim, o próprio reconhecimento de unidades lexicais pode requerer informação pertinente à gramática a ser identificada. A caracterização do modo como enunciados linguísticos são percebidos e representados inicialmente, pela criança, pode, portanto, contribuir para o encaminhamento de uma solução para o problema de aprendibilidade que a aquisição da linguagem apresenta. A teoria linguística, abstraindo-se do modo como a criança percebe os enunciados linguísticos que a ela se apresentam, buscou identificar as propriedades formais que tornam uma língua passível de ser adquirida de forma independente de considerações relativas ao processamento linguístico. Esse encaminhamento veio a requerer sucessivas revisões até que expressões linguísticas passassem a ser caracterizadas como níveis de interface língua/ sistemas de desempenho, o que impõe restrições às propriedades formais que línguas naturais apresentam (Chomsky, 1995). A seguir, recapitularemos brevemente, esse percurso.

Em uma primeira formulação do problema da aquisição da linguagem, a criança teria de identificar as regras específicas da gramática da língua por meio das quais sentenças seriam geradas 
(CHOMSKY, 1965). Para que tal tarefa fosse factível, foi concebido um estado inicial rico de informação pertinente à forma das gramáticas de línguas naturais, denominado Gramática Universal (GU). Este restringiria as gramáticas passíveis de serem identificadas a partir de um subconjunto das sentenças geradas por uma gramática em particular. Ou seja, a criança não identificaria gramáticas com propriedades que não se aplicam as gramáticas de línguas naturais (embora pudessem se aplicar a gramáticas de uma linguagem formal, como, por exemplo, uma linguagem de computação). O programa de pesquisa da linguística gerativista foi então direcionado de modo a caracterizar esse estado inicial (GU), a partir da formalização da gramática de uma ou de várias línguas naturais. Como resultado de cerca de duas décadas de pesquisa, a formulação do problema da aquisição da linguagem foi alterada (CHOMSKY, 1981). Diante do que passou a ser concebido como GU, não haveria regras específicas de uma gramática a serem identificadas. Princípios universais determinariam a forma com que gramáticas de línguas naturais se apresentam e parâmetros universais, com possíveis valores pré-determinados, a serem ajustados a partir da experiência linguística, dariam conta da variabilidade das línguas humanas. Pouca clareza havia, no entanto, quanto ao que seriam os princípios e ao que poderia ser tomado como parâmetros de variação (cf. MEISEL, 1997), o que propulsionou a pesquisa linguística nos anos 80 . Note-se que, nesse momento, questões acerca da natureza dos princípios e dos parâmetros de GU não seriam explicitamente formuladas.

Paralelamente à pesquisa linguística teórica, propriamente dita, estudos de aquisição da linguagem linguisticamente orientados contribuiriam para o desenvolvimento de uma teoria acerca de GU, na medida em que validariam hipóteses ou trariam hipóteses acerca desse estado inicial e das restrições que este imporia, com base em dados da produção espontânea da fala de crianças ou de julgamento de gramaticalidade por crianças já inseridas na gramática da língua (cf. TAVAKOLIAN, 1981; GUASTI, 2004). Hipóteses acerca do processo de aquisição também viriam a ser formuladas em termos estritamente formais, a partir da concepção abstrata do problema de aprendibilidade trazido pela teoria linguística (cf. PINKER, 1987; GIBSON \& WEXLER, 1994). Questões pertinentes ao processamento do material linguístico pela criança não seriam, contudo, consideradas nesse modo de abordagem.

A pesquisa psicolinguística em aquisição da linguagem tem como foco a extração de informação gramaticalmente relevante nos dados da fala e não aderiu unânime ou uniformemente à hipótese de um estado inicial rico de informação específica do domínio da língua. Estudos de orientação mais empirista rejeitariam esse estado inicial (BATES \& MCWHINNEY, 1987; MCWHINNEY,1987; RUMELHART \& MCCLELLAND, 1987). Aqueles de orientação menos empirista tenderiam a buscar res- 
trições de ordem cognitiva para a forma das línguas que minimizassem o que seria atribuído a GU (BEVER, 1970), ou a assumir a idéia de aprendizagem guiada por fatores inatos (innate guided learning), oriunda de estudos etológicos (GOULD \& MARLER, 1987; MARLER, 1991), compatível com uma idéia de GU, embora sem um comprometimento explícito com a concepção de estado inicial então veiculada na teoria linguística (JUSCZYK \& BERTONCINI, 1988).

Uma vertente da pesquisa psicolinguística em aquisição da linguagem voltada para o processamento do sinal da fala pela criança viria questionar o pressuposto de que o input do processo de aquisição pode ser concebido em termos de sequências de elementos do léxico (cf. MORGAN \& DEMUTH, 1996). Segundo a hipótese do bootstrapping (desencadeamento, inicialização) fonológico, contornos prosódicos seriam informativos acerca de possíveis fronteiras oracionais e sintagmáticas, sendo que tais fronteiras seriam, elas próprias, informativas acerca de fronteiras lexicais. Assim sendo, propriedades rítmicas, alongamento de vogais, acento tônico poderiam ser tomados como pistas na análise do material linguístico de modo a torná-lo acessível a um processador sintático. Propriedades fonotáticas e padrões distribucionais em geral poderiam, por sua vez, ser informativos quanto ao modo como unidades lexicais e sintáticas são constituídas (MORGAN \& DEMUTH, 1996). Uma análise distribucional, de natureza estatística, poderia, assim, fazer uso de recursos cognitivos comuns entre domínios, uma vez direcionada por fatores inatos, ou mais especificamente, por um estado inicial, passível de ser concebido em termos de uma GU em que se prevê uma interface fonologia/sintaxe (NESPOR \& VOGEL, 1986; SELKIRK,

4 Em Chomsky (2005), tem-se que as idéias subjacentes à guinada teórica dos anos 90 estariam presentes desde o início da proposta gerativista (pelo menos desde 1977). Estas só não teriam vindo a público porque, no contexto da época, opor-se à idéia de que línguas podem variar entre si de forma imprevisível mostrava-se mais premente do que enfatizar o papel de fatores não especificamente linguísticos na forma das gramáticas. Diante disso, as considerações que aqui apresentamos podem ser vistas como decorrentes da apreciação do que veio a público, ou de como isto foi percebido no contexto da pesquisa em aquisição da linguagem até a década de 90. 1986; TRUCKENDRODT, 1999). Não haveria, portanto, uma incompatibilidade necessária entre a proposta gerativista e abordagens psicolinguisticas para a aquisição da linguagem em que se considera que a análise do sinal acústico da fala (ou de qualquer meio físico em a língua se apresente) é conduzida de forma a otimizar ou viabilizar a aquisição de uma língua.

A pesquisa linguística voltada para GU viria constatar que o tratamento do problema da aquisição da linguagem, abstraindo-se questões pertinentes ao processamento linguístico, seria inviável. ${ }^{4}$ A necessidade de se incorporarem, na formalização da gramática de línguas naturais, representações de interface (língua/sistemas de desempenho), assumindo-se uma faculdade de linguagem em sentido amplo, em que a relação entre a língua e outros sistemas cognitivos é explicitamente prevista, veio, então, a ser enfatizada no Programa Minimalista (doravante PM) (CHOMSKY, 1995-2007).

Este programa se caracteriza por uma revisão metodológica, reduzindo-se ao mínimo os construtos teóricos requeridos na formalização de uma gramática e, particularmente, na caracterização 
de GU. O que é, contudo, mais relevante na proposta minimalista, do ponto de vista de um diálogo com a Psicolinguística, é sua preocupação ontológica. O PM pretende ir além da adequação explanatória do modelo de língua (cf. Chomsky, 1965), buscando fundamentos para os princípios de GU (principled explanations) (seja no aparato processador humano tal como se apresenta ou na própria evolução da espécie). Essa busca leva à redução dos princípios de GU ao princípio da Intepretabilidade Plena nas interfaces aliado a condições gerais de economia. Ou seja, uma expressão linguística, gerada por uma gramática, tem de se apresentar de forma tal que seja passível de ser percebida e articulada pelo aparato processador humano, assim como de ser semanticamente interpretada, nos termos das relações conceptuais/intencionais com que a mente humana é capaz de lidar. Nesse sentido, a seguinte citação é ilustrativa:

"We can regard an explanation of some property of language
as principled, (...), insofar as it can be reduced to the [principles
of structural architecture and developmental constraints that
are not specific to the organ ${ }^{5}$ under investigation, and may be
organism independent] and to conditions that language must
meet to be usable at all - specifically, conditions coded in UG
that are imposed by organism-internal systems with which
FL [faculty of language] interacts. Insofar as properties of I-
-languages can be given a principled explanation, in this sense,
we move to a deeper level of explanation, beyond explanatory
adequacy." (Chomsky, 2005, p.2)

Diante disso, passamos a entender GU como restrições (decorrentes do modo como o aparato processador humano se constituiu) à forma das línguas que venham a ser espontaneamente criadas e adquiridas naturalmente, dada uma faculdade de linguagem que prevê interação entre sistemas cognitivos e um mecanismo formador de estruturas, cuja especificidade linguística é uma questão empírica (cf. CHOMKSY, 2005).

\section{Uma abordagem integrada}

Esta seção vem explicitar de que modo a relação entre língua e cognição pode ser pensada a partir da concepção de língua veiculada na proposta do PM e apresentar a abordagem integrada que vimos desenvolvendo com vistas a contribuir para uma teoria da aquisição da linguagem que explicite o modo como o processo transcorre.

\subsection{A língua na concepção minimalista}

A língua, na concepção minimalista, é um sistema gerativo que opera de modo a gerar expressões linguísticas que servem de interface entre este domínio da cognição e os demais sistemas

O "órgão" sob investigação é a língua. recrutados para que o desempenho linguístico se realize. Cada expressão linguística é vista como um par constituído de uma 
forma fonética e uma forma lógica, que servem de interface com os sistemas sensório-motor (para percepção e articulação da fala) e conceptuais/intencionais (o que possibilita à língua veicular informação de ordem conceptual pertinente a entidades e eventos do mundo). A língua consiste de dois componentes - um sistema computacional universal (conjunto mínimo de operações formais que constroem objetos sintáticos a partir de elementos do léxico de forma recursiva) e um léxico constituído de elementos compostos por traços semânticos, fonológicos e formais. Os primeiros relacionam a língua com sistemas conceptuais e intencionais, os segundos definem a forma fônica dos elementos do léxico, permitindo que estes se tornem acessíveis ao sistema sensóriomotor que atua na articulação e na percepção de enunciados linguísticos, e os últimos, os traços formais, tornam os elementos do léxico acessíveis, como símbolos, ${ }^{6}$ ao sistema computacional (sistema que tem símbolos como input e os transforma em outros que representam aqueles, em função de um algoritmo) para que sejam combinados em uma estrutura sintática.

O sistema computacional universal atua exclusivamente sobre traços formais dos elementos do léxico que constituem o ponto de partida de uma derivação linguística. Os traços formais se apresentam como interpretáveis e não interpretáveis e assumem diferentes valores. Os valores assumidos pelos primeiros representam distinções de ordem conceptual/intencional (gênero, número, pessoa, tempo, aspecto etc) tomadas como gramaticalmente relevantes. Os segundos servem estritamente à computação sintática e são valorados como resultado de seu pareamento com os primeiros no curso da derivação linguística. O resultado dessa operação de concordância (Agree) pode repercutir na morfologia flexional, tornando-se, portanto, visível nas interfaces. Outros traços formais, ainda que não diretamente vinculados a distinções conceptuais (como caso e um traço pertinente à ordenação linear de constituintes) permitem que a sintaxe veicule relações semânticas que se apresentam de forma sistemática nas interfaces.

Observa-se, então, que toda a informação gramaticamente relevante se faz legível nas interfaces. As línguas, ao se constituírem, incorporam distinções conceituais/intencionais aos traços formais do léxico (processo de gramaticalização). Diante das possibilidades que se apresentam à cognição humana, há considerável variabilidade entre as gramáticas de línguas naturais no que concerne às distinções conceptuais/intencionais tomadas como gramaticalmente relevantes. Por outro lado, diante das limitações da cognição humana e do modo como o ser humano se insere no meio exterior a ele, há considerável compartilhamento no que é tomado como gramaticalmente relevante pelas línguas humanas. De forma análoga, dadas as possibilidades do sistema físico que atua na articulação/percepção fala, há espaço para grande variabilidade na constituição de sistemas fonológicos e de padrões 
morfofonológicos que expressem distinções gramaticais. Por outro lado, dado que o sistema sensório-motor é compartilhado pela espécie humana, há restrições que limitam a variabilidade possível na constituição desses sistemas e padrões.

\subsection{O que cabe à criança adquirir}

Diante dessa concepção de língua, cabe à criança, provida de um sistema computacional universal, constituir um léxico, identificar o que a língua toma como traços formais, que valores lhes são atribuídos e que propriedades estes têm, processando a informação que se faz legível nas interfaces da língua com os sistemas envolvidos no desempenho linguistico.

O estado inicial das gramáticas das línguas humanas é, no $\mathrm{PM}$, como em momentos anteriores da teoria linguística, concebido em termos de princípios e parâmetros (CHOMSKY, 1981; 1986). No entanto, diferentemente do que era antes enfatizado, os princípios são fundados em imposições das interfaces. Logo, o modo como a informação gramaticalmente relevante se apresenta nas interfaces é compatível com os recursos de que a criança dispõe para processar o material linguístico que pode perceber. Assim, para que a aquisição de uma língua se torne viável, a criança tem de partir do pressuposto de que pistas prosódicas e padrões recorrentes na interface fônica ${ }^{7}$ sinalizam informação a ser tomada como gramaticalmente relevante, assim com tem de assumir que enunciados linguísticos fazem referência a entidades, eventos e estados. Tais condições, à luz do PM, são garantidas por uma faculdade de linguagem em sentido amplo, a qual prevê a interação entre o sistema da língua e demais sistemas que atuam no processamento linguístico (HAUSER, CHOMSKY \& FITCH, 2002). Desse modo, a proposta minimalista, em certa medida, se assemelha à idéia de restrições cognitivas à forma das gramáticas (BEVER, 1970), pode ser compatível com a idéia de aprendizagem guiada por fatores inatos e possibilita até um diálogo com teorias de aquisição de natureza mais empirista, que admitem restrições de ordem arquitetônica e decorrentes do estado do desenvolvimento neurológico no curso do processo (cf. ELMAN et al., 1996).

Quanto aos parâmetros de variação, a pesquisa linguística converge para a visão de que estes se restringem a propriedades dos traços formais de categorias funcionais (Borer, 1984). Categorias funcionais são classes fechadas cujos elementos codificam, particularmente, informação pertinente à referência a entidades e eventos, assim como à força ilocucionária. Um processo de aqui-

O termo fônica nos parece preferível, quando se considera o processamento, por remeter mais facilmente a propriedades suprasegmentais, cruciais para a percepção do sinal acústico da fala. sição guiado por fatores inatos leva a criança a tomar aquilo que se apresenta de forma regular e sistemática na interface fônica como informação gramaticalmente relevante e a buscar uma interpretação semântica para enunciados linguísticos a partir do pressupostos de que estes remetem a entidades e eventos. 
Os valores que os parâmetros de variação podem assumir são restringidos pelo que é cognoscível e passível de ser percebido/ articulado ou expresso fisicamente pelo ser humano. A criança, ao ser sensível a padrões morfofonológicos deverá, por conta da faculdade de linguagem assumida, buscar uma interpretação semântica para estes, ao lidar com a língua em condições naturais.

Em suma, a pré-condição para a aquisição de uma língua é que a criança tome a fala como informação de interface com a língua (sistema cognitivo, ou língua interna).

O estudo de natureza psicolinguística da aquisição da linguagem tem revelado que o modo como o material acústico se apresenta favorece a identificação das propriedades sintáticas da língua em questão, de forma que, quando a criança se vê diante de uma sequência de elementos do léxico, muito da análise necessária para a identificação da gramática da língua já transcorreu. A seguir trazemos um pouco do que a pesquisa psicolígústica tem obtido a partir da hipótese do bootstrapping fonológico.

\subsection{Processamento na interface fônica e desencadeamento do processo de aquisição}

O conceito de interface fonética do PM é compatível com a concepção de aquisição da língua veiculada pela hipótese do boostrapping (desencadeamento) fonológico (MORGAN \& DEMUTH, 1996; JUSCZYK, 1997; GERKEN, 2001). O processamento do sinal da fala é vinculado a um calendário de desenvolvimento, e se realiza de forma automática desde os primeiros contatos com a língua, ainda na fase intra-uterina (LECANUET, 1998; LECANUET et al., 1992). Ao fim do primeiro ano de vida, além de estar inserida no sistema fonológico da língua, a criança está no ponto de adquirir informação morfológica, fundamental para a identificação da gramática da língua em questão (cf. GERKEN, 2001).

Uma das distinções cruciais que a análise do material acústico pode prover é entre elementos de classe fechada e aberta do léxico. Já nos primeiros dias de vida, a criança percebe distinções acústicas que podem ser úteis para essa diferenciação. Itens funcionais (elementos de classes fechadas), em geral, se distinguem de elementos lexicais (elementos de classe aberta) por suas propriedades fônicas. Os primeiros tendem a apresentar um número mínimo de sílabas (ou moras), com um núcleo simples, sendo preferencialmente átonas, e realizam-se por meio de fonemas não marcados ou subespecificados, de baixa amplitude (MORGAN, SHI \& ALLOPENNA, 1996; SHI, MORGAN \& ALLOPENNA, 1998; SHI, WERKER \& MORGAN 1999). Além disso, são altamente frequentes e têm distribuição característica, tornando-se previsíveis no contexto sintático. Os segundos, por outro lado, não obedecem a um padrão fônico característico, existem em grande número, com frequência variável, não sendo, portanto, previsíveis 
em função do contexto sintático. As propriedades que facilitam essa distinção são comuns a diferentes línguas, como, constatado no inglês, mandarim e turco (Shi, MORGAN \& ALLOPENNA, 1998) e bebês, desde os três dias de vida, mostram-se sensíveis a variações de ordem fônica relevantes para a distinção dessas classes (SHI, WERKER \& MORGAN 1999).

Diferentes habilidades desenvolvidas ao longo do primeiro ano de vida vêm contribuir para essa distinção, tais como o reconhecimento de padrões fonotáticos específicos da língua materna, aos oito meses de vida (JUSCZYK, CUTLER \& REDANZ, 1993) e localização de fronteiras de palavras, com base na integração de informação prosódica e fonotática, aos nove meses de idade (ASLIN ET AL.1998; JUSCZYK 1997). Assim, por volta dos 10-11 meses, o bebê passa a poder distinguir, na fala na fluente, o que deve ser representado como elementos de categorias funcionais e lexicais do léxico em aquisição.

Evidências neurofisiológicas dão suporte às conclusões de uma série de estudos comportamentais por meio da técnica da escuta preferencial (cf. para a descrição da técnica, ver NAME \& CORREA, 2006), que apontam para a sensibilidade de crianças a itens funcionais ao fim do primeiro ano de vida. Para verificar a sensibilidade de bebês a distinções no estímulo fônico, que possam ser relevantes para a identificação gramática, estes são apresentados a enunciados linguísticos, ou passagens em fala fluente, normais e modificados. Modificações tais como a substituição de elementos funcionais como determinantes, auxiliares e a preposição por pseudo-itens - elementos monossilábicos não pertencentes à língua, ainda que em conformidade com seu padrão fonológico - permitem avaliar em que medida a criança se mostra sensível a essa classe de elementos. Crianças de 10-15 adquirindo inglês mostraram-se sensíveis a essas alterações, ouvindo por mais tempo passagens normais do que modificadas (SHADY, 1996), o que pôde ser constatado em respostas eletrofisiológicas do cérebro por volta dos 11 meses de idade. A amplitude dos potenciais evocados pelas histórias modificadas foi significativamente mais baixa do que a dos evocados por histórias normais, sugerindo maior demanda na atividade neuronal por parte do estímulo não imediatamente reconhecível (SHAFER ET AL. 1998). Nessa idade, uma análise sintática no âmbito do DP (sintagma determinante) parece ser conduzida, como sugerem os resultados de estudo com bebês adquirindo alemão (HÖHLE \& WEISSENBORN, 2000). Diferentes grupos de bebês foram familiarizados com sequências de determinante e nome, do tipo der Kahn [o barco]; das Tor [o portão], e com nomes dissílabos como Vulkan e Pastor, cujas segundas sílabas são semelhantes aos nomes da outra condição. Se as crianças do grupo apresentado a um DP reconhecem o determinante, devem ser capazes de reconhecer os nomes em novos DPs com outros determinantes. O mesmo não seria esperado do 
grupo apresentado aos nomes dissílabos isolados. Os resultados sugerem que bebês de 11 meses, diferentemente de bebês de 8 meses, se comportaram como previsto, ouvindo por mais tempo a condição em que os nomes tinham sido previamente apresentados precedidos por determinantes.

Uma série de estudos com a técnica da escuta preferencial conduzidos com bebês de 9 a 18 meses em aquisição do português brasileiro traz resultados compatíveis com a percepção de determinantes na fala fluente por crianças de 14 meses (NAME, 2002; NAME \& CORREAA, 2003) ${ }^{8}$, e com o reconhecimento do padrão morfofonológico de afixos verbais por volta dos 10 meses de idade (BAGETTI, 2009; BAGETTI \& CORRÊA, 2010). Evidências de processamento de ordem semântica também podem ser obtidas, uma vez que, por volta dos 9 meses, a criança demonstra atenção às propriedades comuns entre membros de uma classe pelo processo de nomeação (WAXMAN, 2006).

Diante dessas evidências, observa-se que a distinção fundamental entre as grandes classes ou categorias do léxico (funcionais e lexicais) se estabelece com base em distinções passíveis de serem captadas na interface fônica.

\subsection{A inicialização do sistema computacional}

Ainda que os resultados da pesquisa orientada pela hipótese do bootstrapping fonológico convirjam para a distinção entre classes de elementos funcionais e lexicais ao fim do primeiro ano de vida, não fica suficientemente claro como seria feita a passagem da percepção de elementos de classe fechada e aberta para a representação das grandes classes do léxico (funcional e lexical).

O que há de mais distintivo na faculdade de linguagem humana é a possibilidade de um sistema computacional ter acesso, via traços formais, a elementos de um léxico que (diferentemente de elementos do léxico de linguagens formais), se relacionam com sistemas conceituais/intencionais e sensório-motor, por conta de suas propriedades semânticas e fonológicas. Essa possibilidade deve-se ao fato de padrões ou regularidades presentes na interface fônica sinalizarem propriedades formais e serem reconhecidos como indicativos das mesmas. É, portanto, a relação entre o que há de sistemático na língua e propriedades formais o que permite explicar a passagem de uma análise do sinal da fala para o domínio da sintaxe.

A distinção entre elementos de classe fechada e aberta por volta dos 10 meses de vida, juntamente com o reconhecimento de padrões pertinentes a ordem, que toma por base distinções rítmicas percebidas em tenra idade (NESPOR, GUASTI E CHRISTOPHE,1996; CHRISTOPHE ET AL., 2003; GOUT \& CHRISTOPHE, 2006), daria origem a um léxico mínimo, em que se 
e lexicais (classes abertas), assim como informação pertinente a ordem, vinculada a estas. Os elementos desse léxico mínimo estariam, portanto, subspecificados, pois cabe à criança identificar as distinções de natureza conceptual/intencional tomadas como gramaticalmente relevantes na língua, assim como refinar padrões de ordem à medida em que categorias funcionais e lexicais são progressivamente delimitadas. Padrões morfofonológicos, uma vez identificados em elementos de classes fechadas (determinantes e afixos, por exemplo), têm de ser representados como informação morfológica, semanticamente interpretável. Padrões de ordem ou a morfologia de caso vinculada a elementos lexicais, por sua vez, têm de ser tomados como pertinentes à codificação gramatical de relações semânticas de natureza proposicional. A interpretação semântica do que se apresenta como padrões morfofonológicos assim como a identificação da informação sintática que morfemas de caso ou padrões de ordem apresentam são, portanto, requisitos para a completa especificação das propriedades dos traços formais de categorias funcionais, no curso do desenvolvimento linguístico. Assim, é por conta do processamento na interface fônica, assim como do processamento na interface semântica, impulsionado pelo pressuposto de que enunciados linguísticos remetem a entidades e eventos, que a aquisição de uma língua procede, a partir do segundo ano de vida da criança.

\subsection{A gradual especificação de traços formais e interação entre domínios}

A gradual especificação dos traços formais dos elementos funcionais (de classe fechada) do léxico irá depender da identificação de padrões morfofonológicos variados no interior de sub-classes fechadas do léxico (determinantes, auxiliares e afixos verbais, por exemplo). Variações nos padrões morfofonológicos são indicativas do número de valores passíveis de serem assumidos por um traço formal. No português brasileiro (PB), por exemplo, teríamos variação entre elementos morfologicamente não-marcados e marcados quanto a gênero (masculino/feminino), número (singular/plural) e pessoa $\left(3^{\mathrm{a}} / 1^{\mathrm{a}}\right)$ no âmbito de determinantes; variação morfofonológica pertinente a tempo (presente/passado/ futuro), aspecto (perfeito/imperfeito), modo (realis/irrealis) no âmbito dos afixos verbais. Crianças de 18-27 meses, adquirindo o português, revelam, por exemplo, sensibilidade a alterações entre a expressão morfofonológica do aspecto perfeito/imperfeito, ainda que sua interpretação semântica seja tardia (LIMA-RODRIGUES, 2007). É, portanto, via o processamento na interface semântica que a criança acabará por representar as distinções conceituais/ intencionais que padrões morfofonológicos sinalizam.

O pressuposto de que enunciados linguísticos remetem a entidades e eventos mostra-se relevante para essa progressiva 
especificação de traços. Um DP, uma vez delimitado, pode ser tomado como uma expressão referencial. A informação semântica obtida a partir da referência pode contribuir, por exemplo, para a interpretação da marcação morfológica de número no PB em termos de pluralidade. Constamos que crianças de 22 meses tendem a tomar como referente de um DP plural que contém um pseudo-nome (os dabos, por exemplo) figuras com vários elementos de um mesmo tipo (objetos inventados). Constatamos ainda que a informação relativa a número gramatical é extraída do determinante visto que crianças adquirindo o PB tratam de forma indiferenciada DPs como os dabos e os dabo (dada a co-existência de variantes da língua) e que crianças adquirindo o PE (Português europeu) (em que não há tal coexistência de variantes) ainda que dêem mais respostas indicativas de interpretação do DP como plural para a forma os dabos, dão mais respostas desse tipo para a forma os dabo do que para a alternativa o dabos, tratada, predominantemente, como DP singular (tal como o lápis, por exemplo) (CORREA, AUGUSTO \& FERRARI-NETO, 2005; CASTRO et al., 2009). O processo de especificação de traços formais não deixa de pressupor, contudo, concordância no âmbito do DP. Isso fica claro no caso do gênero gramatical em português. Diante de DPs como $o$ daba e $a$ dabo, por exemplo, a tendência manifesta por crianças de cerca de 22 meses é tomar a informação de gênero expressa no determinante como indicativa do gênero a ser atribuído a um nome novo, seja este inanimado (CORRÊA \& NAME, 2003) ou animado, tanto em PB quanto em PE (CORREA, AUGUSTO \& CASTRO, 2010). Essa atribuição requer que o DP tenha sido analisado como tal e o morfema de gênero seja tomado como indicativo de concordância (CORREA, 2001; NAME, 2002; CORREA \& NAME, 2003).

Em suma, o pressuposto da concordância entre traços formais interpretáveis/não interpretáveis parece ser necessário para que padrões morfofonológicos sejam tomados como indicativos dos valores assumidos por traços formais, e o pressuposto de que DPs atuam como expressões referenciais é necessário para que esses valores sejam semanticamente interpretados. Ambos os pressupostos podem ser vistos como um modo de aprendizagem guiado por fatores inatos, sendo que o uso da concordância como instrumento de aquisição pode ser visto como um recurso especificamente linguístico.

A identificação de padrões morfofonológicos e sua interpretação semântica (não necessariamente correspondente à do adulto) não garante, contudo, a codificação morfofonológica na produção da fala pela criança. Este processo mostra-se particularmente custoso, o que acarreta um desbalanceamento entre o que a criança percebe e e representa e o que produz. No que concerne à produção da fala, a criança minimiza custos de processamento atendo-se ao que há de mais informativo - os traços semânticos 
de elementos de categorias lexicais. Logo, elementos funcionais tendem a ser omitidos. Além disso, elementos funcionais relacionam-se mais diretamente aos sistemas intencionais, dado seu papel na referência (CORREA, 2008). A habilidade de estabelecer referência por meios linguísticos envolve relações entre o domínio da língua e domínios da cognição mais ampla com a qual a língua interage. No caso específico da referência definida/indefinita, por exemplo, seu estabelecimento envolve questões pertinentes à Teoria da Mente (capacidade de atribuir ao outro conhecimento e estados mentais, crenças e intenções, diferentes dos seus), uma vez que a seleção do valor de um dado traço na produção da fala requer que se leve em conta a informação acessível ao interlocutor no discurso. O estabelecimento desse contraste também envolve operações de quantificação, uma vez que um artigo definido pode implicar unicidade na referência (João pegou a maçã - implica que só há uma maçã no universo de discurso) e o artigo indefinido, no português, por exemplo, pode ser tomado como numeral. Logo, espera-se que a produção e a interpretação semântica do traço de definitude do determinante envolva um custoso processo de desenvolvimento, como pode ser constatado (CORREA, AUGUSTO \& ANDRADE-SILVA, 2008). A adequação da referência ao contexto pode ainda pressupor o desenvolvimento de uma teoria cognitiva pragmática da relevância (WILSON \& SPERBER, 2001), o que irá permitir ao falante selecionar a informação de ordem intencional a ser ostensivamente expressa gramaticalmente, possibilitando assim, ao ouvinte, identificá-la de forma inequívoca (LONGCHAMPS, em prep.).

É importante ressaltar, de todo modo, que distinções conceptuais/intencionais básicas podem levar à criança a buscar recursos formais de expressão antes de identificar como a língua as apresenta. É o que parece acontecer com o modo gramatical, que veicula distinções conceptuais/intencionais entre realis/irrealis, as quais são expressas desde cedo, com parcos recursos linguísticos (oposição entre finito/não finito, por exemplo) e cuja aquisição completa passa por um longo processo dependente de habilidades de processamento não disponíveis em tenra idade, como o processamento de estruturas complexas (cf. LONGCHAMPS, 2009).

Em suma, de acordo com a proposta teórica com que vimos trabalhando, a inicialização do sistema computacional se dá a partir da distinção de classes fechadas (funcionais) e abertas (lexicais), aliada à informação relativa a ordem, representadas no léxico por um mínimo de traços formais. Essa inicialização possibilita que uma análise sintática (parsing) seja conduzida, a partir da qual categorias funcionais e lexicais são progressivamente diferenciadas. Variações entre padrões morfofonológicos sinalizam distinção de valores de um dado traço formal. O pressuposto de que enunciados linguísticos remetem a entidades e eventos impulsiona o processamento na interface semântica, por meio do qual 
as distinções conceptuais/intencionais expressas na morfologia vêm a ser interpretadas. O processamento na interface semântica e a total especificação dos traços formais de categorias funcionais é, contudo, um processo custoso que pode depender da interação entre a língua e outros sistemas cognitivos. E uma vez que estes interagem, a língua pode ter um papel no desenvolvimento de aspectos da cognição mais ampla, como tem sido aventado e discutido com relação ao papel da complementação sintática no desenvolvimento dos estágios mais avançados da Teoria da Mente (de VILLIERS, 2004; AUGUSTO \& CORREA, 2009; VILLARINHO \& MARCILESE, 2009) e pode ser constatado no desenvolvimento de habilidades numéricas (MARCILESE, 2011).

Assim sendo, uma abordagem psicolinguística para aquisição da linguagem aliada a uma concepção minimalista de língua fornece um quadro teórico que focaliza diretamente o problema de aprendibilidade que a aquisição de uma língua materna apresenta, e possibilita a exploração de diferentes aspectos do desenvolvimento linguístico.

\section{Para concluir}

Este artigo teve como principal propósito demonstrar como o problema da aprendibilidade que a aquisição da linguagem apresenta requer a articulação linguística/psicolinguística. Esboçamos, então, um procedimento de aquisição da linguagem que caracteriza a passagem de uma análise de base prosódica e distribucional do material da fala no primeiro ano de vida para a análise sintática de enunciados linguísticos, assim como a progressiva especificação de traços formais de categorias funcionais. Para isso, conciliou-se a hipótese do bootstrapping fonológico com uma concepção minimalista de língua e de faculdade de linguagem. O pressuposto da concordância, guiando a análise de relações locais entre segmentos identificados como membros de classes abertas e fechadas foi enfatizado, assim como o foi o pressuposto da referência a entidades, estados e eventos como desencadeador do processamento na interface semântica. Esse último apresentase mais complexo por envolver possíveis relações entre a língua e outros sistemas cognitivos ou por requerer habilidades de processamento mais avançadas (como o processamento de sentenças complexas). Consideramos, assim, que o estabelecimento de um diálogo entre teoria linguística, a partir da proposta minimalista, e uma abordagem procedimental para a aquisição da linguagem pode ser produtivo.

A proposta minimalista favorece a convergência de abordagens formalistas e funcionalistas, uma vez que traços formais podem ser vistos como decorrentes de gramaticalização, na constituição das línguas humanas. Favorece também a convergência de abordagens para a aquisição da linguagem que partem de diferentes perspectivas epistemológicas, uma vez que restrições 
à forma das gramáticas são tidas como decorrentes de imposições das interfaces entre a língua e sistemas que atuam no desempenho linguístico. Entendemos essas convergências como indicativas de amadurecimento teórico. Assim, a nosso ver, o estado-da-arte que hoje se apresenta, ainda que longe de ser amplamente reconhecido, dá indícios de que nos aproximamos de um melhor entendimento da natureza da linguagem e do processo de aquisição de uma língua. Um melhor entendimento desse processo mostra-se fundamental quando se consideram problemas de desenvolvimento linguistico e de habilidades a este vinculadas.

\begin{abstract}
The learnability problem of language acquisition is viewed as requiring a both linguistic and psycholinguistic treatment. Difficulties for an effective joint approach to this problem are identified. An integrated approach is proposed which reconciles the phonological bootstrapping hypothesis with a minimalist conception of language. The early distinction between closed and open lexical classes is considered to be fundamental to the initialization of a universal computational system. Linguistic development is characterized as the progressive specification of the formal features of the functional categories, as processing at the phonetic and semantic interfaces proceeds. Directions for future research on language acquisition in the light of this approach are suggested.

Keywords: language acquisition; learnability; innately guided learning; bootstrapping; minimalism; phonetic interface; semantic interface; formal features.
\end{abstract}

\title{
REFERÊNCIAS
}

ASLIN, R.; SAFFRAN, J.; NEWPORT, E. Computation of conditional probability statistics by 8-monthold infants. Psychological Science, n.27, p.321-324, 1998.

AUGUSTO, M. R. A. ; CORREAA, L. M. S. O papel da língua no desenvolvimento de habilidades cognitivas superiores: avaliando hipóteses linguísticas sobre a teoria da mente. In: Anais do XV Congresso da ASSEL-Rio, p. 1-16, 2009.

BAGETTI, T. Um estudo experimental do processamento na interface fônica e da análise sintática inicial: o papel de elementos funcionais na aquisição da linguagem. Tese de Doutorado, 2009. 
BAGETTI, T.; CORREAA, L. M. S. The early recognition of verb affixes: evidence from Portuguese. Proceedings of the 35th Annual Boston University Conference on Language Development, Boston, 2010. BATES, E., \& MACWHINNEY, B. Competition, variation and language learning. In: MACWHINNEY, B. (Ed.), Mechanisms of language acquisition. Hillsdale, NJ: Erlbaum, 157-194, 1987.

BEVER, T. G. The cognitive basis for linguistic structures. In: J.R. HAYES (ed.) Cognition and the Development of Language. New York: John Wiley \& Sons, 1970.

BLUMENTHAL, A. L. Language and psychology: Historical aspects of psycholinguistics. Oxford, England: John Wiley, 1970. BORER, H. Parameytric Syntax. Dordrecht: Foris, 1984.

CHOMSKY, N. Aspects of the Theory of Syntax. Cambridge, Mass: MIT Press, 1965.

. Lectures on Government and Binding. Dordrecht: Foris, 1981. . Knowledge of Language, its nature, origin and use. New York: Praeger, 1986.

. The Minimalist Program. Cambridge, Mass: MIT Press, 1995. New horizons in the study of language. D.E.L.T.A., v.13, Edição Especial: Chomsky no Brasil, p.1-20, 1997.

Derivation by Phase. MIT Occasional Papers in Linguistics, v.18, Cambridge, Mass: MIT Working Papers in Linguistics, 1999. . On Phases, versão mimeo, publicada em C. P. Otero et. al. eds., Foundational Issues in Linguistic Theory (MIT), 2005.

. Of minds and language. Biolinguistics, v.1, n.1, 2007. CHRISTOPHE, A.; GUASTI, M. T.; NESPOR, M.; VAN OOYEN, B. Prosodic structure and syntactic acquisition: the case of the headcomplement parameter. Developmental Science, n.6, p.213-222, 2003. CORBETT, G.G. Number. Cambridge: Cambridge University Press, 2000.

CORRÊA, L. M. S. Uma hipótese para a identificação do gênero gramatical com particular referência para o Português. In: Letras de Hoje, n.125, p. 289-295, 2001.

. Relação processador linguístico-gramática em perspectiva: problema de unificação em contexto minimalista. DELTA. Documentação de Estudos em Linguística Teórica e Aplicada, v. 24, p. 231-282, 2008.

A identificação de traços formais do léxico pela criança numa perspectiva psicolinguística. Organon, n. 23, p. 71-94, 2009a.

. Bootstrapping language acquisition from a minimalist standpoint: On the identification of phi-features in Brazilian Portuguese. In: PIRES, A.;ROTHMAN, J.. (Org.). Minimalist Inquiries into Child and Adult Language Acquisition: Case Studies across Portuguese. Berlin: Mouton de Gruyter, p. 35-62, $2009 \mathrm{~b}$. 
; AUGUSTO, M.R.A. Possible loci of SLI from a both linguistic and psycholinguistic perspective. Lingua, 121, p. 476-486, 2011. ; NAME, M.C.L. The Processing of Determiner - Noun Agreement and the Identification of the Gender of Nouns in the Early Acquisition of Portuguese. In Journal of Portuguese Linguistics, v. 2, n.1, p.19-43, 2003.

; AUGUSTO, M.R.A. \& ANDRADE-SILVA, H. Definitude e genericidade na aquisição do Português Brasileiro (PB): interface gramática e pragmática. Atas do XV Congresso Internacional de la Asociación de Linguística e Filologia de América Latina (CD), Montevidéu, 2008.

; AUGUSTO, M. R. A. ; CASTRO, A. (a sair). Agreement and markedness in the ascription of gender to novel animate nouns by children acquiring. Portuguese. Journal of Portuguese Linguistics, 2010.

; AUGUSTO, M.R.A; FERRARI-NETO, J. The Early Processing of Number Agreement in the DP: Evidence from the Acquisition of Brazilian Portuguese. Proceedings of the $30^{\text {th }}$ Annual Boston University Conference on Language Development, 2005.

; BAGETTI, T.; NAME, M.C.L. Distinção entre classes abertas e fechadas no processamento da fala ao fim do primeiro ano de vida. Atas do XV Congresso Internacional de la Associación de Linguistica e Filologia de América Latina (CD). Montevidéu, 2008. de VILLIERS, J. Getting complements on your mental state (verbs). In: VAN KAMPEN, J., \& BAAUW, S. (Eds). Proceedings of 2003 GALA Conference. LOT-Utrecht, 2004.

ELMAN, J.; BATES, E.; JONSON, M.; KARMILOFF-SMITH, A.; PARISI, D.; PLUNKETT, K. Rethinking innateness: A connectionist perspective on development. Cambridge, Mass: MIT Press, 1996.

FERGUSON, C.A.; SLOBIN, D.I. (Eds.), Studies of child language development, New York: Holt, Rinehart \& Winston, 1973.

GERKEN, L. Signal to Syntax: Building a bridge. In: WEISSENBORN, J.; HÖHLE, B.Approaches to Bootstraping: phonological, lexical, syntactic and neurophysiological aspects of early language acquisition. Amsterdam/Philadelphia: Jonh Benjamins, v.1, 2001.

GIBSON, E. \& WEXLER, K. Triggers. Linguistic Inquiry, n.25, p. 407-454, 1994.

GOULD, J. \& MARLER, P. Learning by instinct. Scientific American,1987.

GOUT, A.; CHRISTOPHE, A. O papel do bootstrapping prosódico na aquisição da sintaxe e do léxico. In: CORRÊA L.M.S. (ed.) Aquisição da Linguagem e Problemas do Desenvolvimento Linguístico. São Paulo: Edições Loyola/Rio de Janeiro: Editora da PUC-Rio, 2006. GUASTI, M. T. Language acquisition: The growth of grammar. Cambridge, Mass., 2004. 
HAUSER, M.; CHOMSKY, N.; FITCH, W. T. The Faculty of language: what is it, who has it, and how did it evolve? Science, n. 298, p.1569-1579, 2002.

HÖHLE, B.; WEISSENBORN, J. The Origins of Syntactic Knowledge: Recognition of determiners in one year old German children. Proceedings of the $24^{\text {th }}$ annual Boston University Conference on Language Development, v.2, p.418-429, 2000.

JUSCZYK, P. W. The Discovery of Spoken Language, Cambridge, Mass: MIT Press, 1997.

\& BERTONCINI, J. Viewing the development of speech perception as innately guided learning process. Language and Speech, n. 31, 217-238, 1988.

.; CUTLER, A.; REDANTZ, N. Infants' preference for the predominant stress pattern of English words. Child Development, n.64, p.675-687, 1993.

LECANUET, J. Foetal responses to auditory and speech stimuli. In: SLATER, A. (Org.). Perceptual development visual, auditory and speech perception in infancy. Hove, Reino Unido: Psychology Press, p. 317-355, 1998.

.; GRANIER-DEFERRE, C., JACQUET, A.Y., BUSNEL, M.C. Decelerative Cardiac responsiveness to acoustical stimulation in the near term fetus. Quarterly Journal of Experimental Psychology; n. 44b, p.279-303, 1992.

LEVELT, J. Speaking: From intonation to articulation. ACL-MIT Press Series in Natural Language Processing. Bradford Book - The MITPress, Cambridge Mass., London, England., 1989

LIMA-RODRIGUES, C.E.S. Um estudo exploratório do processamento de informação das interfaces na aquisição da linguagem: o aspecto verbal no português. Dissertação de Mestrado - Pontifícia Universidade Católica do Rio de Janeiro, 2007.

LONGCHAMPS, J. O modo verbal na aquisição do Português Brasileiro: evidências naturalistas e experimentais da percepção, expressão e compreensão da distinção realis/irrealis. Dissertação de Mestrado - Pontifícia Universidade Católica do Rio de Janeiro, 2009.

. O Déficit Específico da Linguagem de ordem Pragmática (DEL-Prag): convergência entre Ponto de Vista e Teoria da Mente nos desenvolvimentos linguístico e cognitivo. Título provisório, tese de doutorado em andamento, PUC-Rio.

MACWHINNEY, B. (Ed.), Mechanisms of language acquisition. Hillsdale, NJ: Lawrence Erlbaum, p. 249-308, 1987.

MACWHINNEY, B. The Competition Model. In: MACWHINNEY, B. (Ed.), Mechanisms of language acquisition. Hillsdale, NJ: Lawrence Erlbaum, p. 249-308, 1987. 
MARCILESE, M. Sobre o papel da língua no desenvolvimento de habilidades cognitivas superiores: representação, recursividade e cognição numérica. Tese de Doutorado, PUC-Rio, 2011.

MARLER, P. The instinct to learn. In S. CAREY AND R GELMAN (Eds.), The Epigenesis of Mind: Essays on Biology and Cognition. Hillsdale, NJ: Lawrence Erlbaum Associates, 1991.

MEISEL, J. Parâmetros na aquisição. In: FLETCHER, P. \& MACWHINNEY, B. (eds.) Compêndio da Linguagem da Criança. Porto Alegre: Artes Médicas, 1997.

MORGAN, J. L.; DEMUTH, K. Signal to Syntax: an overview. In: MORGAN, J. L.; DEMUTH, K. (Orgs.). Signal to Syntax: Bootstrapping from speech to grammar in early acquisition). Mahwah, New Jersey: Lawrence Erlbaum Associates, p. 1-22, 1996.

;SHI, R.; ALLOPENNA, P. Perceptual bases of rudimentary grammatical categories: Toward a broader conceptualization of bootstrapping. In: MORGAN, J.; K. DEMUTH (Eds.). Signal to Syntax. Bootstrapping from Speech to Grammar in Early Acquisition. Mahwah, New Jersey: LEA, p.263-283, 1996.

NAME, M. C. L. Sensibilidade a determinantes e atribuição de gênero a novos nomes por crianças adquirindo o português. Anais do XVII Encontro Nacional da ANPOLL, Gramado - RS, 2002.

; CORREAA, L.M.S. Delimitação Perceptual de uma Classe Correspondente à Categoria Funcional D : Evidências da Aquisição do Português. Fórum Linguístico, v.3, n.1, p. 55-88, 2003.

.; CORREAA, L.M.S. Explorando a escuta, o olhar e o processamento sintático: Metodologia experimental para o estudo da aquisição da língua materna em fase inicial. In: CORRÊA, L. M. S. (Org.). Aquisição da Linguagem e problemas do Desenvolvimento Linguístico. Rio de Janeiro: Editora da PUC-Rio, 2006, p.79-100, 2006. NAME, M. C.; CORRÊA, L. M. S. Explorando a escuta, o olhar e o processamento sintático: metodologia experimental para o estudo da aquisição da língua materna em fase inicial. Em L. M. S. CORÊA (Ed.). Aquisição da Linguagem e Problemas do Desenvolvimento Linguístico. Rio de Janeiro: PUC-Rio/Edições Loyola, 2006.

NESPOR, N. \& VOGEL, I. Prosodic phonology. Foris, Dordrecht. 1986. de Gruyter, 2007.

Prosodic Phonology.Studies in Generative Grammar. Mouton NESPOR, M.; GUASTI, M. T.; CHRISTOPHE, A. Selecting Word Order: The Rhythmic Activation Principle. In: KLEINHENZ, U. (ed.) Interfaces in Phonology. Berlin: Akademie Verlag, p. 1-26, 1996. PINKER, S., The bootstrapping problem in language acquisition. In: B. MacWhinney (ed.),Mechanisms of language acquisition. Hillsdale, NJ: Erlbaum, 1987. 
SHADY, M. Infants' sensitivity to function morphemes. PhD Dissertation at Univ. Buffalo, 1996.

SHAFER, V.; SHUCARD, D.; SHUCARD, J.; GERKEN, LA. An Electrophysiological Study of Infants' Sensitivity to the Sound Patterns of English Speech. Journal of Speech, Language and Hearing Research, n.41, p.874-886, 1998.

SHI, R.; MORGAN, J.L.; ALLOPENNA, P. Phonological and acoustic bases for early grammatical category assignment : a cross-linguistic perspective. Journal of Child Language, n. 25, p.169-201, 1998.

.; WERKER, J.; CUTLER, A. Recognition and representation of function words in Englishlearning infants. Infancy, n.10, p. 187-198, 2006.

; WERKER, J. L.; MORGAN, J. L. Newborn infants' sensitivity to perceptual cues to lexical and grammatical words. Cognition, n.72, p. B11-B21, 1999.

RUMELHART, D. E. \& MCCLELLAND, J. L. Learning the past tenses of English verbs: Implicit rules or parallel distributed processing. In: MACWHINNEY, B. (Ed.), Mechanisms of Language Acquisition. Mahwah, NJ: Erlbaum, 1987.

SLOBIN, D.I. Cognitive prerequisites for the development of grammar. In: FERGUSON, C.A.; SLOBIN, D.I. (Eds.), Studies of child language development, New York: Holt, Rinehart \& Winston, p.175-208, 1973.

TAVAKOLIAN, S. (Ed.) Language acquisition and Linguistic theory. Cambridge, Mass.: MIT Press.

WILSON, D. \& SPERBER, D. Relevance theory. In: HORN, L. \& WARD, G. (eds.) Handbook of Pragmatics. Oxford: Blackwell, 2001.

WAXMAN, S. Tudo tinha um nome e de cada nome nascia um novo pensamento: vínculos entre aprendizagem de palavras e organização conceptual no início da aquisição da linguagem. In: CORRÊA L.M.S. (ed.) Aquisição da Linguagem e Problemas do Desenvolvimento Linguístico. São Paulo: Edições Loyola/Rio de Janeiro: Editora da PUC-Rio, 2006.

VILLARINHO, C.; MARCILESE, M. . Complexidade estrutural e cognitiva na compreensão de crenças falsas de segunda ordem. In: Anais do XV Congresso da ASSEL-Rio: Linguagens em diálogo: Pesquisa e ensino na área de Letras. Rio de Janeiro, 2009. 